\title{
Mitt namn är Shaft
}

\section{En populärkulturell ikon i tre olika skepnader}

\begin{abstract}
My name is Shaft. Three times Shaft as a popular-cultural icon
The character of Shaft has taken shape in different times of political polarization of the American society. The aim of this article is to closer examine how the character Shaft is portrayed in three different movies, from different decades. The analysis is specifically pointed towards how Shaft is positioned in relation to time (the time when the film plays out), place (place in urban space) and race (the African-American community). The three Shaft movies plays out in very different times: 1971, 2000 and 2019, that is, during the civil rights movement and active African-American protests, during a period of neoliberal ideals, and in current times, with heightened polarization and strongly voiced Black Lives Matter protests.
\end{abstract}

Keywords: Shaft, African-American, Blaxploitation, popular culture, race

UTIFRÅN EN FÖRSTÅELSE av populärkulturen som en samtidsbarometer riktar vi i denna artikel uppmärksamhet mot Shaft, en populärkulturell symbol som förekommit i olika skepnad, i olika tider och sammanhang. Shaft är en afroamerikansk actionkaraktär som för första gången dök upp på bioduken 1971, i den amerikanska spelfilmen Mitt namn är Shaft (1971). Därefter har samma karaktär återkommit i olika skepnader, i filmer inspelade vid olika tidpunkter. Karaktären Shaft har tagit form under olika perioder av politisk polarisering i det amerikanska samhället, med stark afroamerikansk mobilisering mot orättvisor och rasism: dels i en kontext av 1970-talets medborgarrättskamp (Mitt namn är Shaft [1971]), dels i en kontext av nutidens Black Lives Matter-demonstrationer, motdemonstrationer och dåvarande president Trumps ovilja att tydligt ta avstånd från rasism och motverka en eskalering av oroligheterna (Shaft [2019]). Däremellan har ytterligare en version av Shaft (Shaft [2000]) utspelats i en kontext av millennieskiftets nyliberalism och påbud om "historiens slut". I respektive film framträder en och samma karaktär, om än i lite olika ljus, belyst av den tid och det rum karaktären verkar i. Vad säger då dessa olika versioner av Shaft om den tid, det politiska klimat, och den plats där de utspelar sig? Syftet med artikeln är mot denna bakgrund att närmare undersöka hur karaktären Shaft framställs i tre olika filmer, från tre olika decennier, i den handling som utspelas i respektive film. Analysen riktar specifikt fokus mot hur Shaft positioneras 
i relation till tid (den tid då filmen utspelar sig), plats (det urbana rummet) och ras (den afroamerikanska gemenskapen).

\section{Shaft i tid och rum}

De tre filmer som undersöks i denna artikel spelades in vid olika tidpunkter, av olika regissörer, och delvis med olika rollbesättning. Om vi undersöker filmerna närmare så uppvisar de likheter såväl som skillnader. Gemensamt för filmerna är Shaft i rollen som lagens förlängda arm, som tar sig an allehanda hot, i form av knark och organiserad brottslighet, och bringar lag och ordning i staden, närmare bestämt New York.

Den första filmen hade premiär 1971 (på svenska med titeln Mitt namn är Shaft), som den första i en serie av sammanlagt tre filmer (med Shaft rensar stan [1972] och Shaft och människosmugglarna [1975]). Shaft spelades i samtliga dessa filmer av Richard Roundtree, som fick sitt genombrott med just denna huvudroll. När det första filmen i serien kom marknadsfördes Shaft talande som "Hotter than Bond, cooler than Bullit", positionerad som en svart motsvarighet till två av samtidens etablerade vita actionhjältar: den brittiske superspionen Bond (om än hetare) och den hårdkokte amerikanske polisen Bullitt (om än coolare). Filmen ingick i en bredare filmgenre, Blaxploitation, som med filmer som Sweet Sweetback's baadasssss song (1971), Superfly (1972) och Blacula blodsugaren (1972) marknadsfördes för både en afroamerikansk och en bredare ungdomspublik med intresse för afroamerikansk populärkultur. Med filmens framgångar kom blaxploitation att introduceras till en bredare tittarskara. Även om det finns paralleller mellan produktioner inom denna genre och produktioner inom andra genrer, inte minst deckar- och western-genren, så kan vi här notera att de klassiska rollerna är omvända, med afroamerikanska huvudrollsinnehavare och med vita ofta förpassade till roller som tidigare varit mer gängse för afroamerikaner, det vill säga som skurkar, förövare och korkade bifigurer (Lawrence 2012). Värt att notera är dock att manus till filmerna Mitt namn är Shaft (1971) och Shaft rensar stan (1972), liksom de romaner som tjänade som förlagor, skrevs av en vit man, Ernest Tidyman (1970). I många fall hade blaxploitation-filmerna särskilt inspelade soundtracks, av kända afroamerikanska artister såsom James Brown och Curtis Mayfield. Soundtracken bidrog till att skapa en tydlig stil och dramaturgi, inte sällan med politiska undertoner. Inom genren blaxploitation fanns en stark betoning av det urbana livet, där platsen tillskrevs stor betydelse: "Blaxploitation cinema played a critical role in introducing controversial illustrations of urban life to widespread audiences and set the stage for a new era of black representation in popular culture" (Engels 2014:76). I Shaft, liksom i många av andra blaxploitation-filmer, är en afroamerikansk maskulinitet framträdande (Robinson 1998; Henry 2004; Bausch 2013). I fallet Shaft illustreras detta inte minst av valet av namn på både huvudfigur och filmtitel, vars språkliga undertext tydligt anspelar på sexualitet: som amerikanskt slangord kan shaft dels som substantiv betyda penis, dels som verb betyda sätta på (i sexuell mening). Denna gestaltning kan ses i ljuset av en långvarig tradition i USA, med rötter tillbaka till slaveriets tid, inom vilken afroamerikansk maskulinitet på olika sätt har demoniserats. Shaft, liksom blaxploita- 
tion i dess helhet, var del av ett bredare politiskt och populärkulturellt sammanhang, starkt präglat av fattigdom och tydlig polarisering, som bland annat tog sig uttryck i våldsamma protester och konfrontationer runt om i amerikanska städer. I spåren av det sena 1960-talets politiska klimat förekom en stark kollektiv mobilisering, inte minst i form av medborgarrättsrörelsen, där social rättvisa och kamp mot rasism var framträdande på den politiska agendan.

En av de krafter som var en tongivande del av denna mobilisering var Svarta pantrarna (Black Panther Party), som var särskilt inriktade på just den rasism och de ojämlika sociala villkor som drabbade landets afroamerikanska befolkning. Mobiliseringen bestod av såväl systemkritik och militans som lokalt gräsrotsarbete med fokus på utbildning, vård och omsorg (Nelson 2011). Detta sammanhang bidrog till att kulturen radikaliserades, med politiska undertoner i både musik och film (Ryan \& Kellner 1988; Eyerman \& Jamison 1998).

År 2000 utkom en ny filmatisering av Shaft, med Samuel L. Jackson i huvudrollen. Filmen regisserades av John Singleton, som tidigare regisserat bland annat filmer som Boyz N the Hood (1991) och Livets hairda skola (1995), som kretsar kring kriminalitet, droghandel och gängstrider förlagda till sönderfallande amerikanska stadskärnor. Singleton var tillsammans med bland andra Spike Lee tongivande inom 1990-talets våg av "new black realism"-filmer (Watkins 1998; Bausch 2013). Liksom inom blaxploitation spelade musiken här, först och främst i form av hiphop, en viktig roll. Filmbolaget marknadsförde filmen till en bred ungdomspublik, bestående inte bara av unga med afroamerikansk bakgrund, vilket bidrog till att förankra Shaft i populärkulturens mittfåra. Denna filmatisering av Shaft utspelas i en helt annan kontext än den första Shaft-filmen: i ett New York som Neil Smith (1996) benämnt som en "revanschistisk stad" (revanchist city). Det sena 1990-talets New York, där filmen om Shaft nu utspelas, är starkt format av neoliberala ideal, där marknaden tjänar som modell för hur samhället ses och organiseras. Enligt dessa ideal bör den enskilda individen ges frihet att på egen hand ta ansvar för sitt liv och sin framtid. Dessa ideal utgör grund för en slags revanschism, riktad mot minoriteter och mot en allmän strävan efter social rättvisa, som benämns politisk korrekthet (Smith 1996). Vid denna tid är Svarta pantrarna, liksom andra delar av det sena 1960- och tidiga 1970-talets medborgarrättsrörelse, politiskt detroniserat, inte minst som ett resultat av polisens repressiva bemötande (Eyerman \& Jamison 1998; Nelson 2011). I stället formas samtiden av en "efter-medborgarrättsideologi" (post-civil rights ideology), som med fokus på individens eget ansvar för sitt liv och sitt välbefinnande tenderar att upprätthålla snarare än utmana den vita minoritetens privilegier i det amerikanska samhället (Bonilla-Silva 2001). Utvecklingen kan bland annat skönjas i ett gradvis skifte från kollektiv politisk kamp till individuellt självförverkligande i det amerikanska samhället (Henry 2004).

År 2019 utkom den senaste filmen om Shaft, återigen med Samuel L. Jackson i huvudrollen. Filmen regisserades av Tim Story, som tidigare regisserat science fictionfilmer och komedier. Filmen har också mer tydliga inslag av komedi än de båda föregående filmerna. Den är mindre politisk än föregångarna, samtidigt som den tar form i en tid starkt präglad av politisk polarisering, något som också kommer 
till uttryck i den samtida populärkulturen, inte minst inom film (jämför Izzo 2015). Produktionen inleddes mot slutet av Barack Obamas tid vid makten, som landets första afroamerikanska president, strax innan Donald Trump tillträdde. Den politiska polariseringen blir alltmer påtaglig mot slutet av 2010-talet, med Trump vid makten. Trumpadministrationen har gett prov på såväl auktoritära tendenser som rasism riktad mot minoriteter såsom muslimer, latinos och afroamerikaner, samtidigt som dess marknadsliberala politik lett till fördjupad ojämlikhet (Giroux 2018). Detta har i sin tur lett till en stark opposition mot administrationens politik. En sådan opposition har inte minst kommit till uttryck inom samtida amerikansk populärkultur, i form av en rad uppmärksammade filmer med öppet politiska och samhällskritiska budskap, framför allt ifråga om rasism, såsom Black Panther (2018) och BlacKkKlansman (2018). I spåren av Metoo-rörelsen har dessutom en "folklig feminism" växt fram som en reaktion mot en alltmer rumsren "folklig misogyni" i spåren av Trumps öppna angrepp på kvinnor och feminism (Banet-Weiser 2018), vilket "presents a great challenge for the full range of women's rights globally" (Girard 2017:13).

\section{Analytisk ansats och metodologisk reflektion}

Med avstamp i denna historiska inramning är det dags att presentera vår analys av de tre filmerna. I artikeln närmar vi oss populärkulturen som en slags samtidsbarometer. Genom att närmare undersöka populärkulturen kan vi med andra ord lära oss något om samhället. I populärkulturen åskådliggörs nämligen rådande normer och ideal, men också pågående skeenden och förändringar (Bennett \& Woollacott 1987; Kellner 1995). Populärkulturen kan därmed bidra till att både legitimera och reproducera rådande maktförhållanden i samhället. Samtidigt finns det inom populärkulturen alltid en viss potential att utmana rådande normer, exempelvis genom att artikulera och sprida alternativa sätt att se på världen (Dolby 2003).

I linje med en sådan förståelse kan populärkulturen ses som bärande en politisk dimension, som kan komma till uttryck både implicit och explicit (Street, Inthorn \& Scott 2013). För att relatera till Hall (1997b:259) närmar vi oss populärkulturen som en domän där det utspelar sig en ständig kamp "to represent someone or something in a certain way", det vill säga en slags "representationens politik" (politics of representation). Samtidigt kan populärkulturen ses som bärande en pedagogisk dimension, som består i att människor genom att ta del av och använda sig av populärkulturen, de uttrycksformer och tolkningsrepertoarer som den tillhandahåller, lär sig att bli del av samhällets gemenskap, enligt gängse normer (Dolby 2003).

I denna ständigt pågående representationens politik formas människor till subjekt, genom att på olika vis positioneras diskursivt, exempelvis i populärfilm, som vi riktar uppmärksamhet mot i just denna artikel. Analytiskt fokus riktas särskilt mot subjektspositionen Shaft i de tre filmer som undersöks. Subjektsposition avser här den specifika position som ett subjekt intar i en diskurs (Hall 1997a). En subjektsposition har ingen given mening eller något inneboende värde. Varje subjektsposition konstrueras diskursivt, det vill säga tillskrivs mening i specifika kontexter (Törrönen 2001:216). Det 
innebär att olika subjekt positioneras i relation till andra subjekt, lokaliserade i både tid och rum. Den analys som presenteras i denna artikel riktar fokus mot hur huvudkaraktären eller subjektet Shaft positioneras i relation till andra subjekt i respektive film, i form av den afroamerikanska gemenskap som befinner sig i den urbana miljö där respektive film utspelar sig. I analysen visar vi hur tre olika skepnader av Shaft tar form, i relation till samtidens politiska uttryck. Vår analys av filmerna presenteras i kronologisk ordning, med start i den första filmen om Shaft från 1971.

Analysen har genomförts enligt följande. Inledningsvis gjordes en översiktlig kartläggning av samtliga filmer genom att titta på samtliga filmer i en följd. På så sätt fick vi en sammanhängande förståelse av varje film för sig och filmerna tillsammans, vad gäller dramaturgi och ramberättelse. Under detta skede gjordes anteckningar om nyckelsscener, skeenden, aktörer och huvuddrag. Dessa anteckningar tolkades därefter med utgångspunkt i den förståelse av populärkulturen som samtidsbarometer som presenterats ovan. Utifrån denna tolkning av materialet i dess helhet gjordes ett urval av ett antal nyckelscener, som därefter undersöktes mer i detalj och transkriberades ordagrant. I nästa steg genomfördes en fördjupad analys av dessa utvalda scener, som påvisar vissa särdrag för respektive film när det gäller hur Shaft positioneras som subjekt i relation till andra subjekt i respektive film, först och främst den afroamerikanska gemenskap som befinner sig i den urbana miljö där filmerna utspelar sig.

När vi tar oss an filmer som handlar om en och samma huvudkaraktär, men som är producerade under olika tider, är det en rad frågor som skulle kunna resas. Hur förhåller sig till exempel filmatiseringar till ursprungliga romaner, i de fall där sådana föreligger? Vilken betydelse har det att olika manusförfattare och regissörer kan vara inblandade i filmer om en och samma huvudkaraktär? I vad mån och på vilket sätt inverkar förändrade produktionsvillkor inom filmindustrin på filmernas innehåll, form och dramaturgi? Vi avser inte att besvara dessa frågor i följande artikel, men några av dessa frågor har diskuterats i tidigare forskning, till exempel av Bennett och Woolacott (1987), i deras studie av den populäre hjälten James Bond och de olika skepnader han tar, i tid och rum. De menar bland annat att Bonds popularitet över tid kan ses i ljuset av att filmerna bygger på flera lager av mening, det vill säga att de knyter an inte enbart till en ideologi, utan till en mångfald av ideologier. Vidare lyfter de fram att publikens mottagande och tolkning inte är given på förhand. Det är exempelvis inte helt säkert att det är bland de tänkta målgrupperna som de största framgångarna nås. En annan iakttagelse de gör är att det inte bara är olika producenter och manusförfattare som är involverade i produktionen av olika filmatiseringar av Bond, utan också olika huvudrollsinnehavare, vilket även har viss betydelse för hur karaktären gestaltas. Det kan alltså finnas en rad faktorer som inverkar på hur en och samma huvudkaraktär gestaltas, i olika tider, som därtill bidrar till huvudkaraktärens popularitet, där det inte alltid är helt givet hur gestaltningen ska tolkas. Oavsett vilket är det intressant att rikta uppmärksamhet mot hur en huvudkaraktär som Shaft, liksom andra motsvarande huvudkaraktärer, antar olika skepnad i olika tider, i relation till just samtida normer och ideal. 


\section{Första upplagan av Shaft - 1971}

Shaft introduceras för första gången för tittaren i en lång sekvens av svepande klipp där huvudpersonen promenerar genom New Yorks gator. Först under tystnad, med ett urbant ljudlandskap i form av bilar och sirener, och därefter ackompanjerad av ledmotivet i dess helhet.

Den inledande sekvensen frammanar en tydlig känsla för staden, dess geografi och gemenskaper. Platsen ges således redan från start en stor betydelse i filmens dramaturgi. I filmen utgör staden inte enbart en kuliss för handlingen, utan framträder som en både signifikant och specifik miljö. Tittaren får följa hur Shaft rör sig genom staden och möter de olika människor han passerar längs vägen.

Ledmotivet framhåller tidigt Shafts roll som förkämpe för afroamerikanernas sak, inte minst $\mathrm{i}$ strofen: "Who is the man that would risk his neck for his brother man? Shaft. Can you dig it?" Sången i ledmotivet mixas i just denna strof upp för att på så vis tydligt understryka Shafts persona. Redan i ledmotivets första strof kan vi samtidigt se hur Shaft presenteras med direkt sexualiserad underton, på ett sätt som tydligt anspelar på sedan länge etablerade stereotyper om afroamerikansk maskulinitet: "Who's the black private dick that's a sex machine to all the chicks? Shaft. Ya damn right".

Handlingen i filmen utspelar sig huvudsakligen i Harlem, som är hårt ansatt av en maktkamp om området mellan olika kriminella gäng. Shaft presenteras som privatdetektiv, och blir snart indragen i konflikten när han kontaktas av den afroamerikanske maffiabossen Bumpy Jonas, som vill ha Shafts hjälp med att hitta sin kidnappade dotter.

Handlingen utspelar sig visserligen främst i Harlem, men det framgår att Shaft inte längre bor i Harlem, utan i en finare lägenhet i Greenwich Village, smakfullt inredd med eleganta möbler och konst. Det understryker i viss mån hans självständighet i förhållande till platsen och lokala maktkamper, men Shaft framstår ändå som en man med täta band till Harlem och dess afroamerikanska gemenskap. I jakten på information får tittaren följa hur Shaft rör sig i omgivningarna och respektfullt hälsar på de människor han möter. Han framträder som tätt knuten till och delaktig i områdets sociala gemenskap, även om han inte längre bor där. Den första Shaft-filmen har här vissa paralleller till western-genren i det att miljön bildar skådeplats för en konflikt mellan två motsatta krafter (jämför Kemp 2012). I Shaft utgör på motsvarande vis en sliten innerstadsmiljö med låg socio-ekonomisk status bakgrund till en konflikt mellan afroamerikaner och den italiensk-amerikanska maffian. Vi kan också notera en parallell mellan huvudpersonen Shaft och den klassiska western-berättelsen om den ensamma främlingen som träder in i och rensar upp i en orolig stad (jämför Wright 1975). Shaft träder visserligen inte fram som främling i den miljö där upprensningen sker, men han är uppenbart inte heller bosatt där, utan kommer - likt westernhjälten - utifrån för att städa upp oredan.

Beskrivningen av området framträder med musikens hjälp. Liksom i andra blaxploitation-filmer utgör musiken en viktig del av filmens berättande. Isaac Hayes soundtrack är speciellt inspelat för filmen. En längre sekvens ackompanjeras till to- 
nerna och texten av låten Soulville, som tydligt anger de villkor som råder i området där handlingen utspelar sig:

Black man, born free

At least that's the way it's supposed to be

Chains that binds him are hard to see

Unless you take this walk with me

Place where he lives has got plenty of names

Slums, ghetto and black belt, they are one and the same

And I call it Soulsville

Any kind of job is hard to find

That means an increase in the welfare line

Crime rate is rising too

If you are hungry, what would you do?

I detta urbana rum utspelas en väsentlig del av filmens dramaturgi, som inte enbart handlar om droghandel, uppgörelser i den undre världen och kidnappning, utan också om ett socialt landskap som är starkt format av ojämlikhet, fattigdom och rasism. Shaft verkar i en stad och ett samhälle som befinner sig i ett påfallande glapp mellan å ena sidan löftet om individens frihet och å andra sidan de ojämlika sociala villkor som inte minst den afroamerikanska delen av befolkningen tvingas leva under. Ojämlikheter på grundval av ras är ett starkt genomgående tema i filmen. Tematiken träder fram i flera korta episoder, exempelvis när Shaft pratar i telefon och på frågan "You got problems, baby?", kvickt svarar: "Heh. Yeah, I got a couple of 'em: I was born black, and I was born poor".

Rasojämlikhetens realiteter framkommer tydligt även i en sekvens där Shaft vinkar till sig en taxi. Taxin stannar till, men lämnar Shaft stående på trottoaren, för att i stället stanna och plocka upp en vit kund en bit längre fram. Shaft hytter förgrymmad med näven och utbrister: "You white mother..." Scener som dessa bidrar sammantaget till att skapa den bredare sociala och politiska inramning där själva handlingen utspelar sig. I relation till de ojämlikheter som Shaft - liksom andra delar av den afroamerikanska befolkningen - möter, agerar han som en slags förkämpe för afroamerikanernas sak och för deras rättigheter.

Shaft använder sin auktoritet för att uppnå sina syften och lierar sig med de krafter som gör det möjligt för honom att uppnå dessa - oavsett på vilken sida av lagen de befinner sig. Inledningsvis riktas misstankarna mot en afroamerikansk Svarta pantrarna-liknande beväpnad grupp, verksam i Harlem, under ledning av den gamla polaren Ben. När Shaft i en sekvens fått tag i gruppen förklarar Ben att de inte har något med kidnappningen att göra. Av samtalet framgår att Shaft och Ben har varit med om en del tillsammans, men att de sedan dess har gått åt varsitt håll i livet. Något senare attackeras de av okända beväpnade män och tvingas fly. Några av gruppens män dödas. Shaft visar en tydlig skepsis mot gruppens militära taktik: "When you lead your revolution, whitey better be standing still”. Ben anklagar i sin tur Shaft för 
att ha sålt ut sig till systemet: "You think like a white man”. Shaft svarar: "And you don't think at all".

Senare i filmen framkommer att det är den italiensk-amerikanska maffian som står bakom kidnappningen. Shaft bestämmer sig därefter för att alliera sig med den beväpnade gruppen, i en gemensam aktion för att frita den kidnappade dottern. Den afroamerikanska maffiabossen Bumpy Jonas, liksom den beväpnade gruppen, befinner sig visserligen i direkt konfrontation med det vita etablissemanget, representerat av polisen, men det är ändå inte de som framträder som filmens verkliga bovar. Skurkarna utgörs snarare av de vita italiensk-amerikanerna och den ansiktslösa vita samhällsordningen.

I filmen skapas karaktären Shaft tydligt i relation till platsen, som del av en bredare afroamerikansk gemenskap. Raskonflikter är ständigt närvarande i berättelsen, inte minst i form av den Svarta pantrarna-liknande gruppen som en aktiv kraft i handlingen. Skiljelinjen mellan svart och vit utgör en central del av filmens dramaturgi och den framträder i en rad sekvenser i filmen. De italiensk-amerikanska maffiakaraktärerna framställs som tydliga karikatyrer. Särskilt i den sekvens där Shaft för första gången möter en av dessa karaktärer, en gänglig figur iklädd kostym och hatt, där följande ordväxling äger rum:

Mafioso: I'm looking for a nigger named John Shaft.

Shaft: You've found him, wop. Sit down.

Mafioso: I was just to take you to a lady, come on.

Shaft: I haven't finished my espresso. Why don't you have some? Maybe they'll put a little garlic in it. If you're nice.

Mafioso: No thanks. But you go ahead. You can get time to have your soul food.

Distinktioner mellan italiensk-amerikaner och afroamerikaner görs utifrån tydliga markörer, i form av nedsättande ordval som wop respektive nigger, och stereotypiska associationer till mat i form av vitlök respektive soul food. Relationen till polisen åskådliggörs framför allt i relation till polisinspektör Androzzi. I flera sekvenser försöker Androzzi pressa Shaft på uppgifter om vad som sker i den upptrappade konflikten, men Shaft vägrar, eftersom han inte vill vara en medlöpare. Androzzi porträtteras visserligen som en del av systemet, men relationen mellan dem är ändå inte konfrontativ, utan snarare rak och ärlig. I scenen där de möts äger följande ordväxling rum:

Shaft: Warms my black heart you so concerned about us minority folks.

Androzzi: Oh, come on Shaft, what is it with this black shit, huh? You ain't so black [håller en svart penna framför Shafts ansikte].

Shaft: And you ain't so white either, baby [håller en vit kaffekopp framför Androzzis ansikte].

Androzzi: You want to play your super heavy black number? 
Det är tydligt att de båda mötts tidigare och har en gemensam jargong. Tonen är rak och ironisk, men respektfull. Shaft respekterar Androzzi, även om han är en del av systemet. Och vice versa. Samma ton går igen i en annan sekvens, där Shaft och Androzzi talar om de upptrappade konflikterna. Androzzi skiljer här på den bild av konflikten som ges inifrån och utifrån området: "It’s hood against hood, on the inside. On the outside, it's black against white". Konflikterna har således flera sidor, och det är viktigt att se gängkriget inte enbart som uttryck för en konflikt mellan vita och afroamerikaner, utan snarare som en territoriell maktstrid, som rör kontrollen över territoriet. Shaft svarar: "You are one wise Caucasian, Vic".

Att Vic dessutom, baserat på namnet Androzzi, uppenbarligen är italiensk-amerikan, pekar också på det fruktlösa och oriktiga i att bedöma individer på basis av stereotyper. Androzzi är italiensk-amerikan, men som polis och försvarare av samhällsordningen också en fiende till den italiensk-amerikanska maffian.

Filmen avslutas med en våldsam slutstrid där Shaft tillsammans med en beväpnad trupp stormar hotellet där den kidnappade dottern hålls fängslad. Striden avslutas med att flickan fritas och trupperna skingras, innan polisen anländer till brottsplatsen. Till tonerna av ledmotivet ringer Shaft i filmens sista scen upp Androzzi för att meddela att fallet är avslutat, att Shaft tillsammans med den Svarta pantrarna-liknande gruppen har gjort grovjobbet och att det som återstår för polisen är att städa upp i den oreda som lämnats. Efter samtalet försvinner Shaft, likt westernhjälten, från platsen, in i mörkret, gående längs gatan. Shaft lämnar därmed filmen som han kom, ensam, oberoende, och som ett med staden.

Om vi i korthet summerar de iakttagelser som vi gjort hittills: I 1971 års version av Shaft träder huvudpersonen starkt fram i relation till det urbana landskapet, som delaktig i specifika lokaliteter och gemenskaper, och särskilt specifikt i de nedgångna delarna av Harlem och i dess afroamerikanska gemenskap. Detta urbana rum är dessutom starkt präglat av rasbaserad ojämlikhet, som formar livet och livsvillkoren för den afroamerikanska gemenskapen. I relation till detta urbana landskap tar karaktären Shaft upp kampen mot ojämlikheten för att skapa rättvisa i staden. Denna kamp för rättvisa framträder emellertid inte som en individuell handling, utan snarare som en kollektiv handling, som inte minst involverar den afroamerikanska militanta gruppen i Harlem. Såsom framgår nedan skiljer sig denna upplaga av Shaft på flera sätt från de versioner av karaktären som framträder i de senare filmerna, producerade 2000 och 2019. Låt oss nu vända oss till den upplaga av Shaft som framträdde vid millennieskiftet, år 2000.

\section{Andra upplagan av Shaft - 2000}

I filmen Shaft (2000) rör sig huvudfiguren i ett betydligt mer uppgraderat och gentrifierat urbant landskap jämfört med den första filmen. Om den första filmen framställer Shaft tydligt i förhållande till platsen, den geografiskt identifierbara nedgångna urbana innerstadsmiljön, så utspelas Shaft (2000) i en märkbart gentrifierad innerstadsmiljö. Likaså är det urbana landskapet överlag generellt mera anonymiserat, med färre ut- 
präglade geografiska markörer för New York. I filmen framträder ingen tydlig relation till vare sig platsen eller till specifika karaktärer. Shaft framträder i hög grad som en isolerad individ. Förutom farbrodern introduceras varken familj eller en vidare social gemenskap. Till skillnad från den första filmen är Shaft dessutom inte längre privatdetektiv utan polis.

Den sociala miljön framträder som en stad starkt formad av neoliberala ideal med individen i centrum, med marknadskrafter som sliter sönder staden och en allt tydligare polarisering. Det urbana landskap som filmen utspelar sig i är präglat av en märkbar uppgradering och gentrifiering. De som inte anses höra hemma i stadens kärna misstänkliggörs och möts av repressiva medel, och pressas ut i stadens periferier.

Filmen inleds med en drömlik sekvens, där Isaac Hayes ledmotiv återknyter till den första Shaft-filmen. I sekvensen kopplas Shaft till sexuell dragningskraft, kvinnor, våld, vapen och pengar. Kopplingen till polisiär verksamhet är framträdande genom återkommande bilder på Shafts NYPD-polisbricka samt handklovar.

Därefter inleds själva filmen med sirenljud när Shaft anländer till en brottsplats. Kameran glider från Empire State Building ner mot en gatumiljö på nedre Manhattan, där Shaft rör sig genom en folksamling. Det framkommer snart att brottet rör ett brutalt överfall på en afroamerikansk man, med tydligt rasistiska förtecken. Shaft träder in $i$ en restaurang, där kundernas klädsel utstrålar urban medelklass i innerstadsmiljö. Vi vet ungefär var restaurangen ligger, tack vare bildsvepet från Empire State Building ner mot gatunivån. Shaft närmar sig en vit ung man, Walter Wade jr. Redan i den första dialogen mellan Shaft och Wade jr signaleras en tydlig klassbaserad arrogans. Wade jr har, bokstavligen, blod på sin hand, vilket Shaft också noterar. Wade jr försöker först spela ovetande om blodet, men erkänner sedan att han slagit ner offret, och hävdar att det skett i självförsvar. Med ett minspel som uppvisar arrogans och känslolöshet inför vad som hänt sammanfattar Wade förloppet på följande sätt: "He started it... and I finished it". Härmed framträder bilden av Wade jr närmast som en känslokall rasistisk psykopat. Under den fortsatta utfrågningen framträder också tydliga klassbaserade spänningar. Denna tolkning stärks ytterligare i sekvensen när Shaft får reda på den gripne Wade jrs namn:

Wade jr: D'you know who my father is?

Shaft: No, do you? Take him out.

Dialogen fortsätter utomhus.

Shaft: Walter Wade Junior. Big Walter Wade's son?

Wade jr: Yes I am.

Shaft: The real estate developer?

Wade jr: Correct.

Shaft: Daddy's a big man, huh?

Wade jr: Big man. Ha. Big man. 
Wade jr uppträder under hela sekvensen arrogant och nonchalant. Den anhållnes närmast psykopatiska drag markeras tydligt utanför restaurangen, på själva brottsplatsen, när offret får dödsryckningar. Wade jr riktar sig till Shaft och säger, hånleende: "Homeboy's got rhythm, huh". Shaft överskrider därefter lagen genom att slå gärningsmannen i ansiktet så att han bryter näsbenet. En vit kollega säger därpå skadeglatt att han väntat länge på att Shaft ska tvingas lämna sitt jobb. Shaft svarar kollegan med att slå till Wade jr ytterligare en gång, följt av frågan: "For that?". Efter denna scen lämnar Shaft brottsplatsen gående, mitt i trafiken, till tonerna av ledmotivet från den första filmen. Liksom den ursprunglige Shaft lämnar han brottsplatsen som en man som tagit lagen i egna händer. Men även om Shaft utmanar och så småningom ställer sig utanför systemet, förblir han ändå en del av det. Med eller utan polisbricka bibehåller han genom hela filmen förtroendet för systemet, i form av lagen och domstolsväsendet, och dess förmåga att skipa rättvisa.

Wade jr får i filmen personifiera rasismen i form av den rasistiske psykopaten. I någon mening framställs därmed rasism huvudsakligen i individualiserade termer, vilket får rasismens mer strukturella dimensioner - som tydligt framträdde i den första Shaft-filmen - att träda i skymundan. I flertalet tillbakablickar på brottstillfället får tittaren se Wade jr fälla rasistiska kommentarer till en för honom okänd afroamerikansk man i sällskap med vita vänner. När den trakasserade mannen därpå sätter en servett med urklippta ögon på Wade jrs huvud (för att likna honom vid Ku Klux Klan), blir det droppen. Wade jr följer mannen ut på gatan och slår oprovocerat och brutalt ner honom med ett järnrör.

En individualiserad förståelse av rasism framträder också i relation till hur poliser porträtteras i filmen. I följande scen markerar Shaft mot en rasistisk jargong inom kåren:

Shaft: What's with the cornbread?

Polis: You got a problem with that?

Shaft: Nazis with badges, that's my problem.

Polis: Nazis?... I see your point. Maybe I should take an ethnic sensitivity workshop, huh? Fuck you.

Shaft: Maybe I should workshop my foot up your ass.

Här framträder Shafts kollega som utpräglat rasistisk och förhållandet mellan kollegorna framstår som synnerligen laddat. I en senare scen rånas Wade jr av två maskerade män på pengar som skulle användas för att låta mörda ögonvittnet $\mathrm{i}$ mordfallet. När de maskerade männen sätter sig i en bil för att ta av sig maskerna visar det sig vara Shaft och hans rasistiska kollega, som nu för en vänskaplig, om än kamratligt rå, jargong. 
Polis: How did I sound?

Shaft: How did you sound?

Polis: Freeze mofo, 'fore I bust a cap in your dome.

Shaft: Pure Notorious P.I.G.

Polis: That means a lot coming from you.

Shaft: How much did we get?

Polis: Hang on, hang on. You are so damn controlling. 42 000. That's a lot of count for a simple murder down here.

Shaft: I know cats that'd take out a whole zip code for that kind of cheese.

Polis: Anyway, It's a one-time favor. Ok?

Shaft: I owe you one. You are still my fucking cracker. You know that, right?

Polis: Fuck you too, cornbread.

Förhållandet mellan Shaft och hans kollega tycks således inte alls präglat av antipati, och rasistiskt hat. Den rasistiska dialog som tidigare utspelats förefaller närmast vara uttryck för en rå, men kamratlig jargong. Därmed avdramatiserar filmen också frågan om strukturell rasism inom poliskåren. Strukturell rasism är därmed en dimension som Shaft (2000) inte tar upp vare sig i samhället i stort eller inom poliskåren.

Trots anklagelser för mord släpps Wade jr på fri fot mot borgen. I scenen efter frisläppandet får tittaren möta Shaft hemma i hans lägenhet. Telefonen ringer och Shaft lyfter luren:

It's Walter Wade. Thanks for breaking my nose that night. My lawyer says that's why I got bail, and that's precisely why I am skiing in Switzerland right now. See you when I see you, slick.

Av scenen framgår således att det är Shafts lagliga övertramp som bidragit till att rättvisa inte skipats. På bordet i Shafts lägenhet ligger en tidning uppslagen, med rubriken: "Race killer skips". Sensmoralen är tydlig: Överträd inte systemets regler! Det får konsekvenser.

Två år senare lyckas Shaft återigen gripa Wade jr, som just kommit hem till USA med privatplan. En ny rättegång väntar. Återigen sätts Shafts tilltro till systemets förmåga att skipa rättvisa på prov. En nyckelscen utspelar sig i rättssalen. På grund av att Wade jr tidigare brutit sin borgen och flytt landet kräver domaren att han lämnar in sitt pass. Men samtidigt uppvisar domaren en tydligt uttalad vördnad inför den åtalades samhällsställning när han i sin dom markerar att:

I believe that young Mr Wade is sincere in his desire to deal with whatever form of judgement this room deems necessary to deliver. Bail is set at one million dollar. 
Wade försätts alltså återigen på fri fot, i väntan på rättegång. Visserligen mot en högre borgen än förra gången (en miljon jämfört med tidigare 200000 dollar), men för Wade jr är den summan ringa och advokaten meddelar omedelbart att borgen betalas. Kameran zoomar därefter dels in den dömdes mäktige far, uppenbart tillfreds med domslutet, dels offrets mor, gråtandes över den orättvisa som utspelats i rättssalen. Scenen avslutas med att Shaft tydligt demonstrerar sitt missnöje med domslutet genom att i protest kasta sin polisbricka och därmed lämna poliskåren. Resten av filmen fortsätter han ändå arbetet med att skipa rättvisa, men nu utanför poliskåren. Han uppfattas ändå som polis, och agerar som en, till exempel genom att aktivt nyttja det sociala kapital och de gentjänster han upparbetat, som polis. Med eller utan bricka förblir Shaft alltså, till skillnad från i den första filmen, en lagens väktare.

I filmens avslutande sekvens är det återigen dags för Wade jr att ställas inför rätta. Utanför domstolen talar Shaft med offrets mor.

Shaft: This morning we have a whole new lineup. We got a new judge. The DA himself is running the prosecution. And we have an eyewitness. Today we gonna get our money's worth.

Offrets mor: I know we will.

Shaft uppträder här igen som upprätthållare av lagen, med fortsatt stark tilltro till det juridiska systemet. Korrupta domare kan visserligen förekomma, liksom enskilda rasistiska poliser, men de utgör individuella undantag. Systemet i sig fungerar. Rasismen är inte institutionaliserad. Men i filmens dramatiska slutscen klargörs att offrets mor slutgiltigt förlorat sin tilltro till det juridiska systemets förmåga att skipa rättvisa. Hon tar lagen i egna händer och skjuter Wade jr till döds utanför domstolen. Eftersom systemet inte förmår garantera rättvisa skipar hon rättvisa på egen hand. I egenskap av representant för systemet (polis) kan Shaft inte på egen hand stoppa Wade jr med våld. Däremot visar han, efter det att Wade jr skjutits, ett sympatiskt, godkännande leende riktat mot modern. Hon står stoiskt stilla, sätts i handbojor av uniformerad polis, medan en kör av röster hörs skalla: "Let her go, let her go".

För att summera våra iakttagelser: Shaft kan i denna film sägas porträtteras som vittne till de ojämlikheter som skapas i en revanschistisk tid, framför allt personifierad av Wade jr. I egenskap av att vara en rik vit överklasskille tillåts han göra i stort sett vad han vill och kan därmed tillåta sig ta brutal "revansch" på en av stadens afroamerikanska invånare. I skarp kontrast till den första filmen tar Shaft här inte politisk ställning genom att gå utanför systemets ramar, för att göra något åt orättvisorna. Snarare fortsätter han att verka inom systemet, genom att sätta sitt hopp till att systemet på egen hand förmår skapa rättvisa. Kampen mot orättvisor har år 2000 flyttat fokus, från gatan, in i rättssalen. Detta kan i sig ses som ett symptom på ett mer individualiserat samhälle, där både orättvisorna och svaren mot dem kan förstås i individualistiska termer, utan någon direkt koppling till kollektiv handling. Även om människor behandlas olika inför lagen, och personer som Wade jr, med makt och pengar, kan slippa straff för sina brott, kvarstår tilltron till det juridiska systemet. 
Filmen avslutas med att Shaft lämnar in sin bricka och sitt tjänstevapen, och lämnar sin polisbana. I filmens sista sekvens, som utspelas över filmens sluttext, försvinner Shaft, till tonerna av Isaac Hayes ledmotiv, i en bil tillsammans med sin farbror, för att starta ett nytt liv som privatdeckare. Till skillnad från den första filmen är det inte en ensam Shaft som lämnar tittaren. I motsats till western-genrens sensmoral är sensmoralen här att ensam inte nödvändigtvis är starkast. Därmed öppnar scenen även om det sannolikt inte alls var medvetet - för Shaft i 2019 års skepnad, där det är just familjen som står i fokus.

\section{Tredje upplagan av Shaft - 2019}

I den färskaste upplagan av Shaft (2019) gestaltas karaktären Shaft framför allt i relation till familjen, och dess olika generationer, snarare än i relation till platsen och ett bredare socialt sammanhang. Det urbana rummet blir liksom i Shaft (2000) snarast en anonym kuliss för det familjedrama som utspelar sig i filmen. Platsen skymtar fram i korta sekvenser, jaktscener och panoramabilder över Manhattans ikoniska skyline, men Shaft ges inte någon direkt relation till platsen. Filmens dramaturgi är snarare koncentrerad till relationerna mellan Shaft och hans familjemedlemmar.

Filmen inleds med en svepande inflygning över ett Manhattan i mörker, en känd skyline, men här saknas den närhet och emfas som utmärkte inledningen på den första filmen om Shaft. Introduktionen tar oss tillbaka till ett Harlem 1989 och en scen där Shaft sitter i sin bil tillsammans med sin flickvän Maya och deras son, JJ, John Shaft jr. I denna inledande scen blir de beskjutna av män utsända av boven med det spanskklingande namnet Gordito. Till tonerna av Isaac Hayes ledmotiv bryter skottlossning ut och scenen avslutas med att Maya en gång för alla lämnar Shaft för att rädda sonen undan våldsamheter av detta slag. Därefter följer en sekvens med tillbakablickar där tittaren får följa Maya, sonen och Shaft över åren 1994, 1997, 2001, 2007, 2009 och 2012 fram till nutiden, med filmklipp från saker som inträffat, inte minst i form av de presenter som sonen har fått av Shaft.

I bakgrunden för filmens dramaturgi finns relationen mellan Shaft och skurken Gordito, som var orsaken till att familjen splittrades. Det framgår tidigt att Shaft fortfarande, tre decennier efter det att den inledande scenen utspelat sig, inte har släppt fallet. Shaft har under hela denna tid varit på jakt efter Gordito. Filmens intrig byggs dock framför allt upp kring relationen mellan far och son, där tittaren får följa hur de tar upp kontakten efter en lång tid utan kontakt. Under filmens förlopp får tittaren följa hur relationen mellan far och son utvecklas. I början av filmen framkommer att sonen jobbar för FBI, medan Shaft, liksom i den första filmen, är verksam som privatdetektiv. Dramaturgin tar fart efter det att JJ:s goda vän Karim hittats död utanför ett nedgånget hus där det visar sig att ett gäng kända knarklangare håller till. Sonen bestämmer sig därefter för att ta kontakt med sin far för att be om hjälp med att lösa fallet.

Filmen igenom gestaltas Shaft som en otidsenlig relik. Det är som om han har stått still i tiden. I filmen är Shaft talande nog kvar i sitt gamla kontor, med samma 
dörr som i den första filmen. Han bär också på normer som hör till en annan tid, inte minst vad gäller synen på relationerna mellan män och kvinnor. I relation till fadern gestaltas sonen som en bärare av samtiden, dess normer och anda. Återseendet mellan Shaft och Shaft jr illustrerar tydligt mötet mellan olika generationer och tider, mellan olika varianter av afroamerikansk maskulinitet (gårdagens i Shaft och samtidens i JJ), i form av tydliga kontraster. När JJ kommer för att träffa sin far öppnas dörren av en yngre afroamerikansk kvinna endast iklädd Shafts uppknäppta skinnrock. Shaft presenterar henne som en utomordentlig pilatestränare. Kvinnan lämnar därefter far och son ensamma och de inleder en konversation. Shaft kommenterar genast sonens klädsel, som i sig blir till en symbol för att sonen - till skillnad från Shaft - har gjort en klassresa. Shaft får sedan syn på en FBI-bricka under JJ:s kavaj och följande scen utspelar sig:

Shaft: Oh-oh, so my blood is collecting checks from the FBI?

$J J$ : That's right.

Shaft: How's it feel, you working for the Man?

JJ: You mean having an actual job? Like... paying taxes? Not living off the grid in an all-cash sublet? It's great.

Shaft: So, you live in the city now? Oh, no, don't tell me. uh, down in Soho, exposed brick loft, with a bi-curious roommate and a little furry-ass dog. And... oh, a farmhouse sink?

JJ: You've been stalking my Facebook?

Shaft: I look like I'm on Facebook, motherfucker? You come in here with your skinny-ass jeans, your button-down Gap shirt and what looks like some badminton fucking Nikes. Ha. Any nigga with two eyes and a dick could read you a mile away. Oh, my, your mum did a hell of a job turning you into a bona fide white boy.

I den första filmen var det Shaft som hade gjort en sorts klassresa, från ghettot till den finare delen av staden. I denna film har sonen gjort motsvarande resa. Tittaren får i en scen se JJ:s lägenhet, som påminner om den lägenhet som Shaft själv huserade i 1971. Skillnaden är dock att JJ inte tycks ha någon relation till ghettot och dess afroamerikanska gemenskap, som fadern i den första filmen om Shaft riktade sin kamp för rättvisa i staden mot. Efter en blöt, stökig klubbnatt hjälper Shaft sin son hem till lägenheten och utbrister, när han väl kommer innanför dörren:

Shaft: Whoo, what the fuck! I feel I just stepped into an apartment display at Pier 1 Imports or something. Oh no, no, no. Is that a lemon tower? You know what that says to me? "I hate pussy".

$J J$ : No, it makes a house a home.

Shaft: No, it makes a... homo house.

JJ: Hey... not cool. You cannot use the H-word anymore. Shaft: Oh, really? So, what are you then? You're a metrosexual? A heteronormative? Cisgender? Fluid. Stop me when I tick your box. 
Kontrasten mellan far och son är tydligt markerad i denna scen. I JJ:s ögon framstår Shaft som bärare av en otidsenlig afroamerikansk maskulinitet, med en vokabulär som han inte anser godtagbar i samtiden. I Shafts ögon framstår JJ, omvänt, som ickemaskulin, potentiell homosexuell. I kontrasten framträder Shaft därtill som tillhörande en lägre social rang. Var och hur Shaft själv bor får tittaren inte veta, men av scenen att döma lever far och son helt olika liv, under helt olika villkor, med helt olika typer av boenden. Trots dessa kontraster, och en minst sagt kärv upptakt på de återupptagna kontakterna, så hittar far och son återigen tillbaks till varandra och lär steg för steg känna varandra. Shaft lär inte minst sonen att inte vara så subtil och defensiv i sina relationer till kvinnor, till exempel i följande sekvens, där Shaft, Shaft jr och dennes vän Sasha tar avsked:

JJ: I'll call you.

Sasha: OK.

JJ: Or, I can text you. We have text history for days, so... I've got my thumbs working on that...

Shaft: Why the hell can't you people just talk to each other. Fuck the text. Just use the phone. Call her. Or better, yeah, take her to dinner. Take her to dinner and debrief her over the meal.

Sasha: Dinner? That actually sounds really nice.

JJ: It does. It really does. Yeah. I'll call you about dinner.

Sasha: Awesome. I'll talk to you later. Bye.

Sasha tittar på Shaft och är på väg att gå. JJ riktar sig till Shaft och säger: "Ok, thanks". Shaft himlar med ögonen. Relationen mellan far och son är på väg att förändras och de möter varandra, från varsitt håll. Efter detta avsked följer en scen där Shaft lär sin son om livet - och framför allt om relationen till kvinnor. På väg till bilen säger Shaft:

You gotta stop being so afraid of women, son. You know, women want a man to be a man. They don't want some pussy. Well, some women want some pussy. And some women want both. That is my preference. That's my preference. But in general, women want a man to be manly.

Den scen som följer inbegriper en slags förhandling om afroamerikansk maskulinitet, vad en afroamerikansk man är och hur en afroamerikansk man är, där olika epoker, och maskulinitetsideal, står mot varandra.

JJ: I'm pretty sure women don't like being told what it is that they like...

Shaft: See, that's the shit I'm talking about. Men used to be men. Now, you millennial motherfuckers are running around worrying about what women think and how they feel and apologizing and shit. It's embarrassing.

JJ: Apologizing is embarrassing? 
Shaft: Yes, men don't apologize. That's a trap they set for us. Real men just own their shit.

$J J:$ No, real men take responsibility for what they do. Real men are strong enough to admit when they're wrong.

Shaft: Real men are strong enough to put their foot in a motherfuckers' ass when they get pissed off.

JJ: What is that? The Shaft family motto?

Shaft: It's an unwritten law...

Shaft får i denna scen återigen representera en annan tid och ett annat sätt att vara, jämfört med sin son, som blir en slags representant för samtiden, dess normer och ideal vad gäller afroamerikansk maskulinitet. Enligt Shafts sätt att se på saken var det bättre förr, när män var verkliga män. JJ vidhåller å andra sidan att riktiga män tar ansvar och erkänner sina brister. Det är en tydlig passning till hans far, som under alla år hållit sig borta och inte återtagit kontakten med sin son. Vi kan här se en underliggande tematik som är del av en väl etablerad tankefigur om den afroamerikanska familjen, dess föreställda tillkortakommanden och annorlundahet, som varit ett återkommande ledmotiv i både amerikansk politisk debatt och populärkultur, inte minst film, nämligen den frånvarande (afroamerikanska) fadern (se till exempel Watkins 1998; Edin \& Nelson 2013). Under filmens gång återknyter dock Shaft relationerna till både son och Maya, och genomgår en slags inre omvandling, från dåtida relik till samtida ansvarsfull man. Vändpunkten är en scen där Shaft efter en våldsam skottlossning i vilken både han, JJ och Maya deltar, ber Maya om ursäkt för att ha utsatt familjen för fara. Shaft visar här att han lärt av sonens goda exempel och är på väg att förändras enligt tidens tecken - och därmed bli en del av samtiden.

Inför den slutgiltiga uppgörelsen gör far och son ett besök hemma hos farfar Shaft, spelad av den ursprunglige Shaft-skådespelaren Richard Roundtree, för att ta del av hans vapenförråd. I denna scen förklaras det att farfar tidigare låtsats vara Shafts farbror, som i den föregående filmen också spelades av Roundtree, huvudrollsinnehavaren i 1970-talets Shaft-trilogi. Roundtree knyter därmed samman dessa tre filmer genom att framträda i alla tre filmerna och representera tre olika generationer av Shaft. Även mellan Shaft och Shaft senior finns en märkbar friktion, även om de fortfarande har kontakt med varandra. Farfar och son bekantar sig med varandra till toner som påminner om Isaac Hayes soundtrack från den första filmen. Musiken används här som ett sätt att knyta an till Shaft i dag med Shaft i det förflutna. Tillsammans beger sig de tre generationerna Shaft till uppgörelsen med Shafts ärkefiende, Gordito.

Shaft skadas vid uppgörelsen och hamnar på sjukhus. Där samlas familjen, son och farfar tillsammans med Maya och Sasha. På uppmaning av de äldre Shafts kysser JJ Sasha. I nästa scen återkommer JJ till FBI-kontoret och hyllas som en hjälte. Han får motta kollegornas hyllningar, och får av chefen veta att han återigen är i tjänst. Men i stället för att ta emot beskedet med glädje svarar JJ: "I'm not coming back. I'm done working for the Man”. Ledmotivet rullar igång. "And the name is Shaft. John Shaft". Utanför polishuset ansluter Shaft och Shaft senior iklädda samma mundering. Till- 
sammans har de, framgår det, startat upp en familje-detektivfirma och i gemensam trupp närmar de sig kameran på väg till firmans första uppdrag. Uppdraget går inte ut på att rädda världen, utan det är fråga om ett ordinärt försäkringsbrott. Shaft har blivit entreprenör. Scenen kan därtill ses som en appell för kärnfamiljen. I båda fallen är scenen symptomatisk för en nykonservativ era, där den neoliberala principen om att ensam är stark inte längre är giltig på samma sätt som tidigare. Individen behöver och stärks i stället av sin sociala omgivning, i form av familjens gemenskap. Samtidigt osynliggörs bredare konfliktlinjer och ojämlikheter i samhället, som på olika sätt och med olika intensitet skymtar fram i de båda tidigare filmerna. Huvudlinjen i Shaft (2019) är snarare relationen mellan tider och generationer.

För att summera de iakttagelser som vi gjort: Shaft bedriver i filmen 2019 återigen en slags kamp, men inte mot social orättvisa, utan snarare mot en modern form av maskulinitet, där män inte längre är män. Rasism är till skillnad från de båda föregående filmerna påfallande frånvarande i denna version av Shaft. Det förekommer inga direkta tecken på orättvisor i filmen - vare sig på grundval av ras eller klass. En klassdimension framträder endast i form av afroamerikansk social mobilitet i JJ:s gestalt, som på sätt och vis personifierar den amerikanska drömmen, medan Shaft närmast framstår som en historisk relik, kvar i den roll och den tid där vi träffade honom i den första filmen. Filmens sensmoral, såsom den framför allt träder fram i filmens avslutande scener, ligger i linje med en samtida nykonservativ strömning: Shaft hittar i någon mening hem, till kärnfamiljen och till rätt tid. Om Shaft (2000) uttrycker en sensmoral att ensam inte nödvändigtvis är starkast så är sensmoralen i Shaft (2019) snarare - i stark kontrast till western-genrens sensmoral - att ensam uttryckligen inte är starkast. Andemeningen säger att också afroamerikaner kan nå framgång, om de väl kämpar, men framför allt om de håller samman och stöttar varandra inom familjen. Möjligen kunde slutscenen mot denna bakgrund tolkas som att klanen Shaft vaknat upp ur en långvarig neoliberal dvala och kommit till insikt om familjens och gemenskapens värde - som afroamerikansk medelklass. Vi kan här se vissa beröringspunkter med Matrix-serien, inte minst illustrerat av den närmast identiska utstyrsel som de tre generationerna Shaft bär när de lämnar handlingen och möter framtiden gemensamt. Samtidigt som det djupt polariserade amerikanska samhället är påfallande okommenterat och frånvarande i denna upplaga av Shaft.

\section{Avslutande reflektioner}

I denna artikel har vi riktat fokus mot hur karaktären Shaft framställs i tre olika filmer, från tre olika decennier. Särskild uppmärksamhet har ägnats åt hur Shaft positioneras i relation till tid (den tid då filmen utspelar sig), plats (det urbana rummet) och ras (den afroamerikanska gemenskapen). Om vi summerar våra iakttagelser så kan vi notera följande:

Den första upplagan av Shaft (1971) är en ledande blaxploitation-film, del av en genre med särskilt fokus på afroamerikanernas situation i nedgångna urbana innerstäder. Filmen riktades till och marknadsfördes dels för en afroamerikansk publik, som 
i blaxploitation-filmerna för första gången kunde se afroamerikanska hjältefigurer på bioduken, och dels för en blandad ungdomspublik, med intresse för afroamerikansk musik och urban subkultur. De relationer som utspelas i filmen speglas i huvudsak utgående från ett perspektiv relaterat till ras, antingen synligt eller latent. Det finns genomgående en stark närvaro av medborgarrättskamp, inte minst i form av en Svarta pantrarna-liknande beväpnad grupp, i filmens dramaturgi och i dess dialoger. Ras är här explicit kopplat till relationen mellan afroamerikaner och italiensk-amerikaner.

Den andra upplagan av Shaft (2000) utspelas i ett USA efter presidenterna Reagan, Bush den äldre och Clinton, och därmed i ett samhällsklimat fomat av konservatism och neoliberalism. Framför allt är frågor om ras och rasism mindre påtagligt närvarande och mera individualiserade än i den första filmen. Rasism framträder i form av den individuelle psykopatiske rasisten snarare än som en systematisk rasism. I dess ställe träder klass fram, främst i form av en klassbaserad ojämlikhet och ett starkt fokus på individualism i den neoliberala staden. Ofta, men inte nödvändigtvis, kopplas klass till ras, med särskilt fokus på de rika och privilegierades särbehandling inför lagen. Denna version av Shaft marknadsfördes på ett tydligare sätt än den första till en blandad publik, vilket kan ha bidragit till att rasfrågan är mer nedtonad.

Arbetet med den tredje upplagan av Shaft påbörjades redan under Obamas tid som president, med ett alltmer högljutt missnöje riktat mot den afroamerikanska presidenten bland neokonservativa och högerextrema vita kretsar. Den hade premiär under Trumps presidentskap, en period utmärkt av ökade rasmotsättningar inte minst på grund av uppmärksammade dödsskjutningar av afroamerikaner, följda av oförsonliga uttalanden av president Trump. Filmen kommer ut i en tid präglad av ökad polarisering, omfattande Black Lives Matter-demonstrationer samt motdemonstrationer. Men i kontrast till Shaft (1971), som har premiär under den pågående medborgarrättskampen, förblir samtidens amerikanska samhälls- och rasklimat i huvudsak okommenterat i Shaft (2019). Kontrasten är tydlig mellan Shaft (2019) och en annan samtida amerikansk film, BlacKkKlansman (2018). I denna film kopplar regissören Spike Lee tydligt tiden där filmen utspelar sig (tidigt 1970-tal) till nutid. I slutet av filmen går fiktion över i en dokumentär slutscen, där Black Lives Matter-demonstrationer möts av brutalt våld av högerextrema motdemonstrationer, som urskuldas av president Trump. Filmens dåtidshistoria kopplar på så vis an till och blir till en direkt kommentar till samtida amerikansk politik. Shaft (2019) utgör ingen sådan kommentar, utan existerar närmast som i ett parallellt universum, där nutidens politiska stridsfråga för den afroamerikanska gemenskapen förblir okommenterad. Fokus riktas mot familjen och betydelsen av generationsöverskridande relationer, medan de frågor om ras, klass och individualism som lyfts fram i tidigare filmer, är underordnade och huvudsakligen frånvarande. Det polariserade politiska klimat som utmärker det samtida USA lämnar inga märkbara avtryck i filmen. Sensmoralen är snarare att Shaft efter en lång tids ökenvandring, där han kommit att bli alltmer ur takt med tiden, återfinner själv i samtiden, genom att hitta tillbaks till familjen och familjens centrala värderingar. Att inte låta dagens politiska polarisering, och den afroamerikanska gemenskapens stegrande protester i form av Black Lives Matter-demonstrationer, sätta något avtryck i filmen är också ett 
ställningstagande, som utmärker och särskiljer den senaste Shaft jämfört med tidigare upplagor. Filmen är distribuerad via Netflix utanför USA, och är således ingen biograffilm, och är liksom den andra upplagan riktad till en mer blandad publik.

Om vi övergår till betydelsen av plats i de tre filmerna så skiljer den sig markant mellan filmerna. I den första upplagan avspeglar sig handlingen i väldefinierade mytologiska platser i New York City, främst Harlem. I de två senare upplagorna är platsen betydligt mera anonym. Berättelsen har omlokaliserats från nedgången innerstadsmiljö till en gentrifierad och uppgraderad innerstadsmiljö i New York. Harlems mytologiska status har en stark närvaro i den första filmen, men någon motsvarande platsidentitet synliggörs inte i de senare filmerna. I stället framträder innerstadsmiljön som påfallande anonym. För den första filmen om Shaft, som utspelar sig under medborgarrättskampen och med rasfrågan i centrum, är den plats där handlingen utspelas också laddad med stark symbolik. I de senare filmerna saknas motsvarande rumslig symbolik, både när det gäller klass (i bägge filmerna synliggörs tydliga markörer för södra Manhattan, men utan att betonas) och familj (i bägge filmerna förblir den uppgraderade miljö där handlingen utspelas tämligen anonym).

Shaft är ett tecken i tiden. I tre upplagor av Shaft, under tre distinkta perioder (1971, 2000 och 2019) framträder Shaft i tre olika skepnader, formad av förändringar i tid och rum. Samtidigt rymmer populärkulturen en mångfald av tecken, varav Shaft endast är ett. Figuren Shaft förändras, liksom tiderna han verkar i. Sensmoralen förändras. I dag, liksom i andra tider, är dock populärkulturen ett politiskt slagfält, där Shaft samsas tillsammans med en mängd andra kombattanter som representanter för samtiden, dåtiden och framtiden. Den första upplagan av Shaft porträtterar aktivt den politiska kamp som försiggick under medborgarrättsrörelsens tid. I tydlig kontrast är den andra upplagan av Shaft betydligt mindre involverad i samtidens politiska kamp, detta trots att handlingen tydligt gestaltar klass-baserade orättvisor formade i en individualiserad neoliberal tid. Den tredje upplagan av Shaft försummar däremot helt att kommentera den politiska kamp som förs i dag. Genom att upphöja familjevärderingar, och samtidigt blunda både för de ojämlikheter som existerar och möjligheterna att bemöta dessa med kollektiv handling, uttrycker filmen däremot ett slags postpolitiskt budskap. Filmen blir till ett eko för den länge etablerade myten om "den amerikanska drömmen", med löften om social mobilitet över generationer.

Vi kan således lära av alla tre upplagor av Shaft, där var och en av dem erbjuder en värdefull grund för att både synliggöra och problematisera det politiska klimatet under varje tidsperiod. Genom att avläsa dessa upplagor av Shaft erbjuds vi inte minst verktyg och möjligheter för att förstå och problematisera vår samtid. John Shaft är en representant för sin tid, men samtidigt en representant för olika tider. Varken Shaft eller tiden står stilla. Omvärlden förändras, och vi med den. Det är en av lärdomarna vi kan dra från (tre upplagor av) Shaft. 


\section{Referenser}

Banet-Weiser, S. (2018) Empowered. Popular feminism and popular misogyny. Durham: Duke University Press. https://doi.org/10.1215/9781478002772

Bausch, K. (2013) "Superflies into superkillers. Black masculinity in film from Blaxploitation to new black realism", The Journal of Popular Culture 46 (2):257-275. https://doi.org/10.1111/jpcu.12025

Bennett, T. \& J. Woollacott (1987) Bond and beyond. A political career of a popular hero. Basingstoke: Macmillan. https://doi.org/10.1007/978-1-349-18610-5

Blacula blodsugaren (1972) Regissör: William Crain. Originaltitel: Blacula. American International Pictures (AIP).

BlacKkKlansman (2018) Regissör: Spike Lee. Focus Features, Legendary Entertainment \& Perfect World Pictures.

Black Panther (2018) Regissör: Ryan Coogler. Marvel Studios \& Walt Disney Pictures.

Bonilla-Silva, E. (2001) White supremacy and racism in the post-civil rights era. Boulder: Lynn Rienner.

Boyz $N$ the Hood (1991) Regissör: John Singleton. Columbia Pictures.

Dolby, N. (2003) "Popular culture and democratic practice", Harvard Educational Review 73 (3):258-284. https://doi.org/10.17763/haer.73.3.1225466106204076

Edin, T.J. \& K. Nelson (2013) Doing the best I can. Fatherhood in the inner city. Berkeley: University of California Press. https://doi.org/10.1525/9780520955134

Engels, D. (2014) "Baadassss gangstas: The parallel influences, characteristics and criticisms of the Blaxploitation cinema and gangsta rap movements", Journal of Hip Hop Studies 1 (1):62-80. https://doi.org/10.34718/S4J2-BP90

Eyerman, R. \& A. Jamison (1998) Music and social movements. Mobilizing traditions in the twentieth century. Cambridge: Cambridge University Press.

Girard, F. (2017) "Implications of the Trump administration for sexual and reproductive rights globally", Reproductive Health Matters 25 (49):6-13. https://doi.org/10.1 080/09688080.2017.1301028

Giroux, H. (2018) The public in peril. Trump and the menace of American authoritarianism. New York: Routledge.

Hall, S. (1997a) "The work of representation", 13-64 i S. Hall (red.) Representation. Milton Keynes: Sage.

Hall, S. (1997b) "The spectacle of 'the Other”, 225-279 i S. Hall (red.) Representation. Milton Keynes: Sage.

Henry, M. (2004) "He Is a 'bad mother*\$\%@!\#'. 'Shaft' and contemporary black masculinity", African American Review 38 (1):119-126. https://doi.org/10.2307/1512235

Izzo, D.G. (red.) (2015) Movies in the age of Obama. The era of post racial and neo-racist cinema. Lanham: Rowman \& Littlefield.

Kemp, P. (red.) (2012) Det här är film. Hela historien frän 1895 till idag. Stockholm: Norstedts.

Kellner, D. (1995) Media culture. New York: Routledge. 
Lawrence, N. (2012) Blaxploitation films of the 1970s. Blackness and genre. New York: Routledge.

Livets hårda skola (1995) Regissör: John Singleton. Originaltitel: Higher learning. Columbia Pictures \& New Deal Productions.

Mitt namn är Shaft (1971) Regissör: Gordon Parks. Orginaltitel: Shaft. Metro-Goldwyn-Mayer (MGM) \& Shaft Productions.

Nelson, A. (2011) Body and soul. The Black Panther Party and the fight against medical discrimination. Minneapolis: University of Minnesota Press.

Robinson, C.J. (1998) "Blaxploitation and the misrepresentation of liberation", Race \& Class 40 (1):1-12. https://doi.org/10.1177/030639689804000101

Ryan, M. \& D. Kellner (1988) Camera politica. The politics and ideology of contemporary Hollywood film. Bloomington: Indiana University Press.

Shaft (2000) Regissör: John Singleton. New Deal Productions.

Shaft (2019) Regissör: Tim Story. Davis Entertainment, Khalabo Ink Society, Netflix, New Line Cinema, Warner Bros. Digital Networks \& Warner Bros.

Shaft och människosmugglarna (1975) Regissör: John Guillermin. Originaltitel: Shaft in Africa. Metro-Goldwyn Mayer (MGM) \& Shaft Productions.

Shaft rensar stan (1972) Regissör: Gordon Parks. Originaltitel: Shaft's Big Score. MetroGoldwyn Mayer (MGM) \& Shaft Productions.

Smith, N. (1996) The new urban frontier. Gentrification and the revanchist city. Hoboken: Taylor \& Francis. https://doi.org/10.4324/9780203975640

Street, J., S. Inthorn \& M. Scott (2013) From entertainment to citizenship. Manchester: Manchester University Press.

Superfly (1972) Regissör: Gordon Parks Jr. Warner Bros.

Sweet Sweetback's Baadasssss Song (1971) Regissör: Melvin van Peebles. Yeah.

Tidyman, E. (1970) Shaft. New York: Macmillan Press.

Törrönen, J. (2001) "The concept of subject position in empirical social research", Journal for the Theory of Social Behaviour 31 (3):313-330. https://doi.org/10.1111/14685914.00161

Watkins, S. C. (1998) Representing. Hip hop culture and the production of black cinema. Chicago: The University of Chicago Press.

Wright, W. (1975) Sixguns \& society. A structural study of the western. Berkeley: University of California Press. 


\section{Författarpresentation}

Peter Ehrström är forskningschef och ämnesansvarig för regionalvetenskap vid Åbo Akademi. Han är även docent i regionalvetenskap, särskilt urban politik, vid Vasa universitet. Hans forskning rör frågor kring transformation och social hållbarhet i städer och stadsnära landsbygd, deliberativ demokrati, deltagande och livslångt lärande, samt platsbaserad identitet och populärkultur.

Magnus Dahlstedt är professor i socialt arbete vid Linköpings universitet. Hans forskning rör frågor om välfärd och medborgarskapande, med särskilt fokus på unga, inkludering och exkludering i migrationens tid.

\section{Kontaktuppgifter författare}

Peter Ehrström

Regionalvetenskap, Fakulteten för pedagogik och välfärdsstudier, Åbo Akademi PB 311, 65101 Vasa, Finland

peter.ehrstrom@abo.fi 